\title{
Effect of Physical Training on the Activity of the Low Km Phosphodiesterase in Heart Ventricular and Skeletal Muscle Tissues of Normal and Diabetic Rats
}

\author{
Gilles Plourde*, M.D., Ph.D. and André NadeauÝ, M.D., F.R.C.P.(C)
}

* Department of Radiology, Montreal General Hospital, Montreal, QC, Canada H3G 1A4

$\hat{Y}$ To whom correspondence should be addressed: Diabetes Research Unit, Laval University Medical Center, 2705 Laurier Boulevard, Ste-Foy, Quebec, Canada G1V 4G2

\section{ABSTRACT}

This study assessed the effect of physical training on the low Michaelis constant cyclic AMP phosphodiesterase (low Km PDE) activity in heart ventricular tissue and three different skeletal muscle tissues of normal and diabetic rats. Rats were rendered diabetic with streptozotocin ( $45 \mathrm{mg} / \mathrm{kg}$ i.v.) and either kept sedentary $(\mathrm{SD}, \mathrm{n}=16)$ or submitted to a progressive 10 -week treadmill running program $(\mathrm{TD}, \mathrm{n}=17)$. Two groups of nondiabetic rats served as trained (TC, $n=17)$ and sedentary controls $(S C, n=15)$. The activity of NAD-linked isocitrate dehydrogenase was significantly increased $(\mathrm{p}<0.001)$ in the gastrocnemius muscle of trained animals, confirming that they were adequately trained. Plasma glucose levels were elevated in SD rats $(18.8 \pm 1.7 \mathrm{mmol} / \mathrm{l})$ compared to those in $\mathrm{SC}$ rats $(7.7 \pm 0.2 \mathrm{mmol} / \mathrm{l}$; mean \pm standard error of the mean $[\mathrm{SEM}], \mathrm{p}<0.001)$. These levels were partially normalized following training $(12.7 \pm 1.7 \mathrm{pmol} / \mathrm{l} ; \mathrm{p}<0.01 \mathrm{vs}$. $\mathrm{SD}$ rats). Plasma insulin levels were significantly reduced in TC rats $(223 \pm 16 \mathrm{pmol} / \mathrm{l})$ compared with those in $S C$ rats $(306 \pm 13 \mathrm{pmol} / 1 ; \mathrm{p}<0.01)$. Similarly, the levels in $\mathrm{SC}$ rats were significantly different when compared with SD rats $(155 \pm 15 \mathrm{pmol} / \mathrm{l} ; \mathrm{p}<0.01)$. In TD rats, plasma insulin levels $(156 \pm 14 \mathrm{pmol} / \mathrm{l})$ were similar to those of SD rats. This suggests that mild diabetes mellitus in the rat can be improved by endurance training and that improved glycemic control may be mediated by an increase in insulin sensitivity. The low $\mathrm{Km}$ PDE activity in the membranes prepared from the four different muscle tissues was not modified by diabetes. Similarly, physical training in normal and diabetic rats did not induce any significant changes in the low Km PDE activity in any of the tissues tested. This suggests that improvements in myocardial contractile function and in glucose homeostasis, as seen in diabetic rats submitted to endurance training, are not associated with changes in PDE .

\section{INTRODUCTION}

Diabetes is associated with a high risk of congestive heart failure (1). The mortality rate during acute experimental myocardial infarction has been shown to be higher in diabetic than in nondiabetic rats (2). 
However, the mechanism responsible for this reduction in the survival rate of diabetic rats has not been established. The mechanisms involved may include an alteration in the activity of the enzyme responsible for the degradation of adenosine 3',5'-cyclic monophosphate (cAMP). It is well recognized that cAMP activates protein kinase, which in turn phosphorylates calcium channels and induces transarcolemmal $\mathrm{Ca}^{++}$entry, which thereby permits myocardial contraction (3). A reduction in cAMP represents a potential mechanism for a decrease in the contractile capacity of the heart. Earlier studies suggested that a deficiency in the production of cAMP may be a fundamental defect in patients with end-stage heart failure $(4,5)$. In theory, a deficiency in cAMP can be the result of two general mechanisms: a decrease in the formation of cAMP by adenylate cyclase or an increase in its degradation by the cAMP phosphodiesterase (PDE). PDE was first identified by Butcher and Sutherland as the enzyme responsible for the hydrolysis of cAMP into 5'-AMP (6). Using ventricular muscle membrane preparations, we have previously observed that the amount of cAMP produced in response to isoproterenol stimulation was reduced in diabetic rats. This diminution was associated with a reduction in the density of $\beta$-adrenergic receptors and with the coupling between the $\beta$-adrenergic receptor and the Gs protein (7). However, the degradation of cAMP by PDE in ventricular membranes of diabetic rats has never been measured. Thompson and Appleman have demonstrated that most tissues contain at least two isoforms of PDE responsible for the degradation of cAMP (8). One PDE isoform is of low molecular weight, has a low Michaelis constant, and is associated with the plasma membrane and sarcoplasmic reticulum. The other isoform has a higher molecular weight, a higher $\mathrm{Km}$, and is found in the cytoplasm.

Improvements in the myocardial contractile function of diabetic rats with physical training is a well-accepted phenomenon (9). Physical training has also been shown to improve the survival rate of diabetic rats submitted to acute myocardial infarction (2). We have previously reported that cAMP production by heart ventricular membranes in response to isoproterenol stimulation was not modified in trained diabetic rats as compared with their sedentary counterparts (7). Since the intracellular quantity of cAMP stems from a balance between its formation and its degradation, it would also seem highly relevant to determine the activity of the enzyme responsible for the degradation of cAMP in these animals. Therefore, the first part of this study was undertaken to investigate the effect of physical training on the low Km PDE activity in ventricular membrane preparations of normal and diabetic rats.

Physical training is also known to improve glucose homeostasis in experimental models of mild diabetes mellitus (10-12). Although this has been explained by an increase in insulin sensitivity in skeletal muscle $(13,14)$, the exact mechanisms responsible for this enhancement remain to be elucidated. Among the many mechanisms possibly involved in the improvement of diabetes mellitus following physical training, modifications in the sympathoadrenal system deserve to be considered. Physical exercise activates the adrenergic system $(14,15)$. This affects blood glucose levels both directly by activating glycogenolysis and gluconeogenesis $(16,17)$, and indirectly by stimulating glucagon secretion (18) and inhibiting insulin secretion (19). We have previously shown that physical training increases the density of ß-adrenergic receptors as well as the formation of cAMP by adenylate cyclase in response to isoproterenol stimulation in soleus muscle membranes of diabetic rats (20). However, until now, no study has reported on the impact of physical training on low Km PDE activity in skeletal muscle of diabetic rats. Therefore, the second part of this study was undertaken to evaluate the influence of diabetes and physical training on the low Km PDE activity in three different types of skeletal muscle: the soleus, the deep portion of the vastus lateralis, and the superficial portion of the vastus lateralis. These muscles are known to be affected differently by endurance training. In addition, they differ in their composition: i) the soleus muscle is composed of $87 \%$ type I (slowtwitch, high oxidative, and low glycolytic), and 13\% type IIa (fast-twitch, high oxidative, and high glycolytic) fibers; ii) the deep red portion of the vastus lateralis muscle is composed of $9 \%$ type I, 56\% type IIa, and 35\% type IIb (fast-twitch, low oxidative, and high glycolytic) fibers; iii) the superficial white portion of the vastus lateralis muscle consists of 3\% type IIa and 97\% type IIb fibers. Type I fibers are well suited for prolonged exercise. Type IIa fibers are recruited along with type I fibers during high-intensity exercise of long duration, and type IIb fibers are recruited during high-intensity exercise of short duration $(21,22)$. 
Interestingly, these muscles also differ in their capacity to change $B$-adrenergic receptor density in response to physical training $(23,24)$.

\section{MATERIALS AND METHODS}

\section{Rats}

Male Wistar rats (207 $\pm 2 \mathrm{~g}$ ) were randomly assigned to four groups: sedentary control (SC), trained control (TC), sedentary diabetic (SD), and trained diabetic (TD). Rats were individually housed at $23^{\circ} \mathrm{C}$ under standard lighting ( 5 a.m. to 7 p.m.) and provided with Purina rat chow and tap water ad libitum. Experimental diabetes was induced by an intravenous injection of streptozotocin (a gift of Upjohn Company of Canada) freshly dissolved in citrate buffer $(200 \mu 1, \mathrm{pH} 4.5)$ at a dose of $45 \mathrm{mg} / \mathrm{kg}$ of body weight in the non-fasted state. This treatment destroys the insulin-secreting cells of the pancreas, thus creating an insulinopenic state. Consequently, there is an increase in plasma glucose, glucosuria, and a decrease in body weight; this state is analogous to type I diabetes mellitus in humans (25). Control rats received an equivalent volume of citrate buffer. Rats treated with streptozotocin were kept in the study only if, one week later, their urinary output was greater than or equal to $15 \mathrm{ml} /$ day and their urinary glucose concentration, measured with Diastix strips (Ames Division, Miles Laboratories, Rexdale, ON) was greater than or equal to $1 \%$. Since rats can survive without hypoglycemic treatment, this represents an animal model of moderate non-ketotic experimental diabetes mellitus (25).

\section{Physical Training}

Exercise training began 10 days after streptozotocin injection and was carried out by having the rats run on a motorized treadmill (Quinton Instruments, Model 42-15, Seattle, WA) set at an $8^{\circ}$ incline, according to a program adapted from Pattengale and Holloszy (26). Rats were trained twice a day, with a 4-hour rest interval, 5 days a week for 10 weeks. They initially ran for $10 \mathrm{~min}$ at $22 \mathrm{~m} / \mathrm{min}$ for 3 weeks, then for $40 \mathrm{~min}$ at $28 \mathrm{~m} / \mathrm{min}$ for 3 weeks, and finally for $60 \mathrm{~min}$ at $31 \mathrm{~m} / \mathrm{min}$ for 4 weeks. At the end of the 10 -week training program, the rats were killed by decapitation. A period of 64 hours between the last session of exercise and decapitation was allotted to dissociate, as much as possible, between a training effect and the immediate postexercise event. The heart and skeletal muscle were rapidly excised, washed in isotonic saline solution, weighed, frozen in liquid nitrogen, and stored at $-80^{\circ} \mathrm{C}$. The white portion of the vastus lateralis was separated from the red portion on the basis of visual appearance. Tissue samples were thawed on the day of experimentation. The ventricles were weighed after removal of the atria, aorta, and epicardial fat.

\section{Preparation of Muscle Membranes}

The muscle membranes were prepared by mincing the tissue with scissors in a $0.32 \mathrm{M}$ sucrose solution at $4^{\circ} \mathrm{C}$, followed by two 10-second bursts with a Polytron homogenizer (Tekmar, Cincinnati, OH) set at high speed. The homogenates were filtered through a triple layer of cheese-cloth and centrifuged at 40,000 g for $20 \mathrm{~min}$. Finally, the pellets were suspended and diluted in incubation buffer $\left(50 \mathrm{mM}\right.$ Tris- $\mathrm{HCl}, \mathrm{pH} 7.4$ at $\left.4^{\circ} \mathrm{C}\right)$ containing $1.1 \mathrm{mM}$ ascorbic acid as an antioxidant and $3 \mathrm{mM}$ EDTA as a protease inhibitor (27), and homogenized with a motor-driven glass-Teflon Potter-Elvehjem (Dyna-mix, Model 143, Fisher Scientific, Pittsburgh, PA) set at high speed to give a final protein concentration of approximately $0.30 \mathrm{mg} / \mathrm{ml}$. Protein concentration was measured according to Lowry et al. (28), using bovine serum albumin as standard.

\section{Phosphodiesterase Assay}

Phosphodiesterase (PDE) activity was measured as described by Loten and Sneyd (29). The assay is based on the measurement of $\left[{ }^{3} \mathrm{H}\right]$-adenosine formation from $\left[{ }^{3} \mathrm{H}\right]$-cAMP subsequent to hydrolysis by PDE and snake venom nucleotidase (29). The reaction was initiated by adding $50 \mu 1$ of membrane preparation to $150 \mu 1$ of 
reaction mixture containing $50 \mathrm{mM}$ Tris- $\mathrm{HCl}, 2.8 \mathrm{mM} \mathrm{MgCl}_{2}, 3.75 \mathrm{mM}$ 2-mercaptoethanol, $0.25 \mu \mathrm{M}$ of unlabeled cAMP, $50 \mu \mathrm{l}$ of snake venom nucleosidase $(2 \mathrm{mg} / \mathrm{ml}$ in $50 \mathrm{mM}$ Tris-buffer, $\mathrm{pH} 7.5)$ and 12,000 cpm of $\left[{ }^{3} \mathrm{H}\right]$-cAMP. All tubes were incubated for $15 \mathrm{~min}$ at $37^{\circ} \mathrm{C}$. Incubation was stopped with the addition of $50 \mu 1$ of $5 \mathrm{mM}$ adenosine in $200 \mathrm{mM}$ EDTA (pH 4.6). Adenosine was separated from cAMP by ion exchange chromatography on a column of anion exchange resin AG 1-X2, 200-400 $\mu \mathrm{m}$ mesh, chloride form, and the radioactivity counted in a liquid scintillation counter. Preliminary experiments revealed that the apparent $\mathrm{Km}$ calculated from Lineweaver-Burk plots (30) for the membrane bound PDE was $0.25 \mu \mathrm{M}$ as observed in the study of Weber and Appleman (31). Snake venom nucleotidase, 2-mercaptoethanol, anion exchange resin (AG 1-X2), and cAMP were purchased from Sigma Chemical Co. (St-Louis, MO). [ $\left.{ }^{3} \mathrm{H}\right]$-cAMP was purchased from New England Nuclear (Boston, MA).

\section{Plasma Glucose and Insulin Levels}

Plasma glucose concentration was determined by an enzymatic method (32). Plasma insulin was measured by radioimmunoassay, using rat insulin as standard and polyethylene glycol for separation (33). Insulin standard was obtained from Novo Research Institute (Copenhagen, Denmark). Polyethylene glycol 8000 was purchased from Biotech Scientifique (Lachine, QC).

\section{NAD-Linked Isocitrate Dehydrogenase (NAD-ICDH) Activity}

The NAD-ICDH activity in the gastrocnemius muscles of rats was measured according to the method of Vaughan and Newsholme (34). Peripheral skeletal muscle adaptation to endurance training results in an increase in the density of mitochondria and in the activity of many oxidative mitochondrial enzymes $(21,35)$. NAD-ICDH is a mitochondrial enzyme of the citric acid cycle and has been previously reported to be a good indicator of physical training in rats $(36,37)$.

\section{Statistical Analysis}

The results are given as mean \pm SEM. Statistical analysis between groups was done by using analysis of variance (ANOVA), and the post-hoc comparisons among treatment groups was done with the Duncan's multiple range test. Similarly, statistical analysis between muscles for the activity of the low Km PDE in SC rats was also performed using ANOVA, followed by the Duncan's multiple range test. $p<0.05$ was taken as statistically significant.

\section{RESULTS}

Some characteristics for the four groups of rats are shown in Table 1. Despite the fact that the initial body weight was similar in each group, a significant $(p<0.01)$ reduction in body weight was observed in the sedentary diabetic rats, the trained control rats, and the trained diabetic rats, when compared to the sedentary control group. In comparison with sedentary control rats, the weight of each of the muscles studied was also less at the end of the 10-week program in the three other groups. In contrast, no significant difference in ventricular weight was observed. The reduction in skeletal muscle weights in the 10 -week trained control rats represents a normal physiologic adaptation to endurance training $(21,35)$, as previously reported $(23)$. The change in the weight of the skeletal muscles observed in the diabetic rats may be explained by insulin deficiency which leads to an increased protein catabolism and muscle wasting (38). The NAD-ICDH activity in the gastrocnemius was significantly reduced in the diabetic rats when compared with that of the sedentary controls, but was significantly increased $(p<0.01)$ following training in both the normal and the diabetic rats. This mitochondrial enzyme is known to increase with physical training $(36,37)$, and the changes observed in its levels confirm that the endurance training program used in this study was of adequate intensity to induce metabolic changes. Plasma glucose levels were significantly $(p<0.01)$ increased in diabetic rats relative to the sedentary controls. In both groups, physical training resulted in a reduction in plasma glucose levels when 
compared to the levels in their sedentary counterparts. Similarly, plasma insulin levels were significantly reduced in trained controls and in sedentary diabetic rats when compared with those in sedentary controls. In trained diabetic rats, plasma insulin levels remained comparable to the values measured in sedentary diabetic rats. This confirmed previous observations that mild experimental diabetes mellitus in the rat can be improved by endurance training (10-12) and that this improvement is at least partly related to an increase in insulin sensitivity (13).

The low Km PDE activity in the cardiac and skeletal tissue from the four groups of rats is shown in Table 2. The low Km PDE activity was not affected by the diabetic state in any of the tissues tested. Similarly, physical training did not influence the low Km PDE activity in either ventricular tissue or in the three types of skeletal muscle of either normal or diabetic rats. Finally, it was noted that the activity of the low Km PDE in sedentary control rats was greater in the deep red portion of the vastus lateralis than in the soleus $(p<0.01)$ but was not significantly different from the white superficial portion of the vastus lateralis muscle.

\section{DISCUSSION}

This study is the first to report the effect of physical training on the low Km PDE activity in ventricular membrane preparations from diabetic animals. Dohm et al. previously reported that the activity of the low Km PDE in heart tissue was unaffected by endurance training (39). However, their study differed in that their rats ran once instead of twice a day, and that their program lasted 7 weeks rather than 10 as in the present study. Nevertheless, our results did not differ from those observed by these authors. Physical training is associated with cardiovascular adaptations such as bradycardia at rest $(40,41)$. These manifestations can be explained at least in part by a decrease in the activity of the sympathetic nervous system (40). To this effect, we have previously shown that the activity of the $\beta$-adrenergic system, as determined by the density of $\beta$ adrenergic receptors and receptor-Gs protein coupling, was reduced in ventricular membranes of trained rats when compared to their sedentary controls. This adaptation was associated with a reduction in the formation of cAMP in response to the stimulation of adenylate cyclase by isoproterenol (42). The data presented here showed that the activity of the low Km PDE was not altered by training. Taken together, our findings suggest that physical training induces a reduction in the production of cAMP by adenylate cyclase in response to isoproterenol stimulation in ventricular membranes and this reduction is not accompanied by a parallel change in the activity of the ventricular plasma-membrane-associated phosphodiesterase. However, in the present study only basal PDE activity was examined. It would have been interesting to measure PDE activity at Vmax or under stimulation with isoproterenol and/or insulin, particularly considering the decreased glucose levels (implying better insulin responsiveness) in trained rats. Further work will be needed to address this issue.

The low Km PDE activity in the ventricular membrane preparation was also not modified by experimental diabetes. Alterations in the activity of this enzyme may be tissue-dependent since previous studies have demonstrated a depressed PDE activity in adipose tissue and liver from streptozotocin-induced diabetic rats (43-45). Alternatively, the difference between our results and those previously reported (43-45) may also be related to a more severe diabetic state in the earlier studies since the dose of streptozotocin used to induce diabetes was $65 \mathrm{mg} / \mathrm{kg}$ compared to $45 \mathrm{mg} / \mathrm{kg}$ used in the present study.

As stated in the introduction, a deficiency in intracellular cAMP production can be associated with an increased risk of heart failure $(4,5)$. This hypothesis is supported by the observation that the inotropic effectiveness of drugs that act to increase intracellular levels of cAMP, such as the $\beta$-adrenergic agonist isoproterenol or the PDE inhibitors milrinone, caffeine, and isobutylmethylxanthine, was markedly reduced in cardiac muscles from patients with heart failure $(4,5)$. In contrast, the effectiveness of inotropic stimulation with drugs that act by a cAMP-independent mechanism, such as the cardiotonic steroids and DPI 201-106, was preserved $(4,5)$. Furthermore, stimulation of intracellular cAMP production by the adenylate cyclase activator forskolin restored the inotropic response to phosphodiesterase inhibitors $(4,5)$. The deficiency of 
intracellular cAMP may be related to down regulation of myocardial $B 1$-adrenergic receptors and to a reduction in the coupling between the receptors and the Gs protein which occur in patients with heart failure (3). It was previously observed in patients with heart failure that the reduction in cAMP content cannot be explained by alterations in the properties of PDE but can rather be explained by an attenuated adenylate cyclase activity (46). We have previously observed that the production of cAMP in response to isoproterenol stimulation was reduced in ventricular tissue of diabetic rats and that this decline was associated with a reduction in the density of ventricular $B$-adrenergic receptors and with a reduction in the coupling between the receptors and the Gs protein (7). Our results suggest that, in the diabetic rat, the production of cAMP by adenylate cyclase in ventricular membranes in response to isoproterenol stimulation is reduced. This reduction is not paralleled by an increase in the activity of the ventricular plasma-membrane PDE.

Physical training is known to improve cardiac function in diabetic rats (9). This has also been observed to improve the survival rate of diabetic rats subjected to myocardial infarction (2). The possibility that these adaptations could be due to an increase in the ventricular level of cAMP and a consequent increase in the contractility of the heart can be evoked. The results previously presented do not seem to support this hypothesis. It was observed that the production of cAMP by heart ventricular membranes in response to isoproterenol stimulation was not modified in trained diabetic rats in comparison with their sedentary counterparts (7). However, we cannot completely exclude the implication of cAMP in the improved cardiac functions of diabetic rats without measuring the activity of the low Km PDE involved in the degradation of cAMP. The results of the present study show that the activity of this enzyme is not influenced by physical training. Therefore, changes in the activity of this enzyme do not seem to be involved in the training-induced improvement of cardiac function of rats with mild experimental diabetes mellitus.

The second part of the present work, carried out in normal and diabetic rats, is the first to compare the low $\mathrm{Km}$ PDE activity in plasma membrane preparations from three different skeletal muscles which differ in their relative proportion of fiber types and to report on the effect of endurance training at this level. First, we observed in sedentary control rats that the activity of the low Km PDE in the red portion of the vastus lateralis was significantly greater than in the soleus but not significantly different from the one present in the white superficial portion of the vastus lateralis muscle. We cannot assess the physiological importance of this variation on the basis of the existing data. However, the order of activity observed for the low Km PDE among the three skeletal muscles tested raises the possibility of an association between skeletal muscle low $\mathrm{Km}$ PDE activity and glycolytic activity. This is because the muscles known to possess a high glycolytic activity, the white and red portion for the vastus lateralis muscle (21), also had a high activity of this enzyme. Further studies would be needed to understand the significance of this observation. On the other hand, the results of the present study demonstrated that physical training had no effect on the low Km PDE activity in skeletal muscles of normal rats. Dohm et al. have previously reported that the activity of the low Km PDE in gastrocnemius muscle was unaffected by endurance training (39). In the present study, we carried out measurements of the low Km PDE activity in three other skeletal muscles. The interest for such a study originated from the observation that each muscle differs in its fiber composition and in the contractile recruitment in response to physical training $(21,22)$. In a previous study $(23)$, we have observed that the basal adenylate cyclase activity also varied among skeletal muscles, but did not seem to be influenced by physical training. In comparison with their sedentary counterparts, the adenylate cyclase response to isoproterenol stimulation was increased by $49 \%$ in the soleus muscle of trained animals, but was not significantly modified in the red and white portion of the vastus lateralis muscle. In the present study, we did not observe any differences in the activity of the low Km PDE in each of these muscles between sedentary and trained rats. Overall, these results suggest that physical training induces an increase in the production of cAMP by adenylate cyclase in response to isoproterenol stimulation only in the soleus muscle and this is not accompanied by a parallel change in the low Km PDE activity.

Our observation that the activity of the low Km PDE was not modified by training in any of the muscles tested suggests that changes at this level are not involved in the beneficial effects of physical training in 
diabetic rats. In a previous study, we have reported that physical training caused an increase in the Badrenergic receptor density and an increase in the production of cAMP in response to isoproterenol stimulation in the soleus muscle (20). Tissue cAMP levels are kept in balance between synthesis mediated by adenylate cyclase and catabolism mediated by PDE. Taken together, the results from the present study and from our previous work (20) suggest that the increased adenylate cyclase activity in the absence of changes in PDE activity would lead to increased levels of intracellular cAMP that may have beneficial metabolic effects.

In conclusion, the results of the present study indicate that the activity of low Km PDE in heart ventricular tissue and in three different skeletal muscles of the rat is not influenced by physical training nor diabetes. This suggests that changes in the activity of this enzyme are not involved in the training-induced improvement of cardiovascular function and glucose homeostasis in rats with experimental diabetes mellitus.

\section{ACKNOWLEDGMENTS}

This work was supported by a grant from the Medical Research Council of Canada and by Le Fonds de la Recherche en Santé du Québec. Gilles Plourde was the holder of a summer studentship from the Quebec Diabetes Association. The authors thank Marie Martin for technical assistance.

\section{REFERENCES}

1. Kannel WB, Hjortland M, and Castelli WP. Role of diabetes in congestive heart failure: the Framingham study. American Journal of Cardiology 34: 29-34; 1974.

2. Nadeau A, Rousseau-Migneron S, and Tancrède G. Exercise training improves early survival rate in diabetic rats submitted to acute coronary artery ligation. Diabetes Research 9: 37-40; 1988.

3. Braunwald E, Sonnenblick EH, and Ross J Jr. Mechanisms of cardiac contraction and relaxation. In: Braunwald E (ed.). Heart Disease, A Textbook of Cardiovascular Medicine, 3rd ed. Philadelphia, PA: Saunders, 383-425, 1988.

4. Feldman MD, Copelas S, Gwathmey JK, et al. Deficient production of cyclic AMP: pharmacologic evidence of an important cause of contractile dysfunction in patients with end-stage heart failure. Circulation 75: 331-339; 1988.

5. Morgan JP, Erny RE, Allen PD, Grossman W, Gwathmey JK. Abnormal intracellular calcium handling, a major cause of systolic and diastolic dysfunction in ventricular myocardium from patients with heart failure. Circulation 81(suppl. III): 21-32; 1990.

6. Butcher RW, and Sutherland EW. Adenosine 3',5'-phosphate in biological materials. Journal of Biological Chemical 37: 1244-1250; 1962.

7. Plourde G, Martin M, Rousseau-Migneron S, Nadeau A. Effect of physical training on ventricular Badrenergic receptor adenylate cyclase system of diabetic rats. Metabolism 40: 362-367; 1991.

8. Thompson WJ, Appleman MM. Characterization of cyclic nucleotide phosphodiesterases of rat tissues. Journal of Biological Chemistry 246: 3145-3150; 1971.

9. Paulson DJ, Kopp SJ, Peace DG, Tow JP. Myocardial adaptation to endurance exercise training in diabetic rats. American Journal of Physiology 252: R1073-R1081; 1987.

10. Tancrède G, Rousseau-Migneron S, Nadeau A. Beneficial effects of physical training in rats with a mild streptozotocin-induced diabetes mellitus. Diabetes 31: 406-409; 1982. 
11. Reaven GM, Chang F. Effect of exercise-training on the metabolic manifestations of streptozotocininduced diabetes in rat. Diabetologia 21: 415-417; 1981.

12. Tan MH, Bonen A, Garner JB, Belcastro AN. Physical training in diabetic rats: effect of glucose tolerance and serum lipids. Journal of Applied Physiology 52: 1514-1518; 1982.

13. Dall'Aglio E, Chang F, Chang H, Wright D, Reaven GM. Effect of exercise training and sucrose feeding on insulin-stimulated glucose uptake in rats with streptozotocin-induced-insulin-deficient diabetes. Diabetes 32: $165-168 ; 1983$.

14. Hartley LH, Mason JW, Hogan RP, et al. Multiple hormonal responses to graded exercise in relation to physical training. Journal of Applied Physiology 33: 602-606; 1972.

15. Galbo H, Holst JJ, Christensen NJ. Glucagon and plasma catecholamines responses to graded and prolonged exercise in man. Journal of Applied Physiology 38: 70-76; 1975.

16. Ellis S. The metabolic effects of epinephrine and related amines. Pharmacological Reviews 8: 485-562; 1956.

17. Himms-Hagen J. Sympathetic regulation of metabolism. Pharmacological Reviews 19: 368-461; 1967.

18. Gerich JE, Langlois M, Noacco C, Schneider V, Forsham PH. Adrenergic modulation of pancreatic glucagon secretion in man. Journal of Clinical Investigation 53: 1441-1446; 1974.

19. Porte D Jr, Williams RH. Inhibition of insulin release by norepinephrine in man. Science 152: 1248-1250; 1966.

20. Plourde G, Rousseau-Migneron S, Nadeau A. Physical training increases the number of ß-adrenergic receptors and adenylate cyclase activity in high-oxidative skeletal muscle of diabetic rats. Metabolism 41: 1331-1335; 1992.

21. Saltin B, Gollnick PD. Skeletal muscle adaptability: significance for metabolism and performance. In: Handbook of Physiology. Skeletal Muscle. Bethesda, MD: American Physiological Society, 555-631, 1983.

22. Armstrong RB, Phelps RO. Muscle fiber composition of the rat hindlimb. American Journal of Anatomy 171: $259-272 ; 1984$.

23. Plourde G, Rousseau-Migneron S, Nadeau A. Effect of endurance training on B-adrenergic system in three different skeletal muscles. Journal of Applied Physiology 74: 1641-1646; 1993.

24. Buckenmeyer PJ, Goldfarb AH, Partilla JS, Pineyro MA, Dax EM. Endurance training, not acute exercise, differentially alters $B$-receptors and cyclase in skeletal fiber types. American Journal of Physiology 258: E71-E77; 1990.

25. Tancrède G, Rousseau-Migneron S, Nadeau A. Long-term changes in the diabetic state induced by different doses of streptozotocin in rats. British Journal Experimental Pathology 64: 117-123; 1983.

26. Pattengale PK, Holloszy JD. Augmentation of skeletal muscle myoglobin by a program of treadmill running. American Journal of Physiology 213: 783-785; 1967.

27. Stiles GL, Strasser RH, Kilpatrick BF, Taylor SR, Lefkowitz RJ. Endogenous proteinases modulate the function of the B-adrenergic receptor-adenylate cyclase system. Biochimica et Biophysica Acta 802: 390-398; 
1984.

28. Lowry OH, Rosenbrough NJ, Farr AL, Randall R. Protein measurement with Folin phenol reagent. Journal of Biological Chemistry 193: 265-275; 1951.

29. Loten EG, Sneyd JGT. An effect of insulin on adipose-tissue adenosine 3',5'-cyclic monophosphate phosphodiesterase. Biochemical Journal 120: 187-193; 1970.

30. Lineweaver H, Burk DJ. The determination of enzymes dissociation constants. Journal of the American Chemical Society 56: 658-666; 1934.

31. Weber HW, Appleman MM. Insulin-dependent and insulin-independent low Km phosphodiesterase from adipose tissue. Journal of Biological Chemistry 257: 5339-5341; 1982.

32. Richterich R, Dauwalder H. Zur bestimmung der Plasmaglucose-konzentration mit der Hexokinaseglucose-6-phosphat-dehydrogenase-methode. Schweizerische Medizinische Wochenschrift. Journal Suisse de Medecine 101: 615-18; 1971.

33. Desbuquois B, Aurbach GD. Use of polyethylene glycol to separate free and antibody-bound peptide hormones in radioimmunoassays. Journal of Clinical Endocrinology 33: 732-738; 1971.

34. Vaughan $\mathrm{H}$, Newsholme EA. The effects of $\mathrm{Ca}^{2+}$ and ADP on the activity of NAD-linked isocitrate dehydrogenase of muscle. FEBS Letters 5: 124-126; 1969.

35. Booth FW, Thomason DB. Molecular and cellular adaptation of muscle in response to exercise: perspectives of various models. Physiological Reviews 71: 541-585; 1991.

36. Holloszy JO, Oscai LB, Don IJ, Molé PA. Mitochondrial citric acid cycle and related enzymes: adaptative response to exercise. Biochemical and Biophysical Research Communications 40: 1368-1373; 1970.

37. Benzi G. Endurance training and enzymatic activities in skeletal muscle. In: diPrampero PE, Poortmans JR (eds.). Physiological Chemistry of Exercise and Training. New York, NY: Karger, Basel, 165-174, 1981.

38. Kimball SR, Flaim KE, Peavy DE, et al. Protein metabolism. In: Rifkin H, Porte D Jr (eds.). Ellenberg and Rifkin's Diabetes mellitus: Theory and Practice. New York, NY: Elsevier Science, 41-50, 1990.

39. Dohm GL, Pennington SN, Barakat H. Effect of exercise training on adenyl cyclase and phosphodiesterase in skeletal muscle, heart, and liver. Biochemical Medicine 16: 138-142; 1976.

40. Scheuer J, Tipton CM. Cardiovascular adaptations to physical training. Annual Review of Physiology 39: 221-251; 1977.

41. Tipton CM. Training and bradycardia in rats. American Journal of Physiology 209: 1089-1094; 1965.

42. Plourde G, Rousseau-Migneron S, and Nadeau A. ß-adrenoceptor adenylate cyclase system adaptation to physical training in rat ventricular tissue. Journal of Applied Physiology 70: 1633-1638; 1991.

43. Solomon SS. Effect of insulin and lipolytic hormones on cyclic AMP phosphodiesterase activity in normal and diabetic rat adipose tissue. Endocrinology 96: 1366-1373; 1975.

44. Solomon SS, Palazzolo M, Mcpherson J, Smoake AL. Effects of experimental diabetes and insulin on cyclic AMP phosphodiesterase and its protein activator in rat adipose tissue. Diabetes 30: 372-376; 1981. 
45. Solomon SS, Silberberg M, and Palazzolo MR. Measurement of protein activator levels in experimental diabetic rat adipose tissue. Biochemical and Biophysical Research Communications 86: 379-386; 1979.

46. Schmitz W, Eschenhagen T, Mende, Müller FU, Neumann J, Scholz H. Phosphodiesterase inhibition and positive inotropy in failing human myocardium. In: Hasenfuss G, Holubarsh CH, Just H, Alpert NR (eds.). Cellular and molecular alterations in the failing human heart. Steinkopff Verlag Darmstadt, 65-71, 1992.

\section{BIOGRAPHY}

Gilles Plourde received his B.Sc. and M.Sc. degrees in Physical Activity Sciences and in Nutrition from Laval University (Quebec, Quebec) in 1986 and 1989, respectively. He received his Ph.D. degree in Experimental Medicine from Laval University in 1993 and his M.D. degree from the University of Montreal (Montreal, Quebec) in 1995. He is presently a first-year diagnostic radiology resident at McGill University. His research on phosphodiesterase activity was conducted as part of his Ph.D. degree at the Diabetes Research Unit of Laval University Medical Center. This project was funded by the Medical Research Council of Canada, Le Fonds de la Recherche en Santé du Québec and the Quebec Diabetes Association.

Copyright (C) 1995 by MJM 